\title{
Scientists Use GEANIE to Study Isotopes of Iridium and Europium to Improve Radiochemical Diagnostics in Nuclear Devices
}

J. Becker

November 21, 2002

U.S. Department of Energy

Law rence

Livermore

National

Laboratary 


\section{DISCLAIMER}

This document was prepared as an account of work sponsored by an agency of the United States Government. Neither the United States Government nor the University of California nor any of their employees, makes any warranty, express or implied, or assumes any legal liability or responsibility for the accuracy, completeness, or usefulness of any information, apparatus, product, or process disclosed, or represents that its use would not infringe privately owned rights. Reference herein to any specific commercial product, process, or service by trade name, trademark, manufacturer, or otherwise, does not necessarily constitute or imply its endorsement, recommendation, or favoring by the United States Government or the University of California. The views and opinions of authors expressed herein do not necessarily state or reflect those of the United States Government or the University of California, and shall not be used for advertising or product endorsement purposes.

This work was performed under the auspices of the U. S. Department of Energy by the University of California, Lawrence Livermore National Laboratory under Contract No. W-7405-Eng-48.

This report has been reproduced directly from the best available copy.

Available electronically at http://www.doc.gov/bridge

Available for a processing fee to U.S. Department of Energy

And its contractors in paper from

U.S. Department of Energy

Office of Scientific and Technical Information

P.O. Box 62

Oak Ridge, TN 37831-0062

Telephone: (865) 576-8401

Facsimile: (865) 576-5728

E-mail: reports@adonis.osti.gov

Available for the sale to the public from

U.S. Department of Commerce

National Technical Information Service

5285 Port Royal Road

Springfield, VA 22161

Telephone: (800) 553-6847

Facsimile: (703) 605-6900

E-mail: orders@ntis.fedworld.gov

Online ordering: http://www.ntis.gov/ordering.htm

OR

Lawrence Livermore National Laboratory

Technical Information Department's Digital Library

http://www.llnl.gov/tid/Library.html 


\section{Scientists Use GEANIE to Study Isotopes of Iridium and Europium to Improve Radiochemical Diagnostics in Nuclear Devices}

\section{Introduction}

Radiochemical diagnostics play an important role in helping scientists understand the detonation of a nuclear device. Sometimes some elements or isotopes are inserted as radiochemical detectors at various locations in the nuclear device. During the detonation of the device, these detectors are subjected for a short time to the intense flux of neutrons emitted through fission and possibly through fusion of light elements (usually deuterium and tritium). After the detonation, the radiochemical detectors and their long-lived activation products are retrieved from the area where the underground explosion took place. These radiochemical samples are analyzed to extract information about how the device operated. A large amount of such radiochemical data exist from past nucleardevice tests.

\section{Radiochemical detectors}

Radiochemical detectors with an energy threshold in their activation cross section (i.e., the energy-dependent probability that incident neutrons produce the long-lived reaction product of interest in the detector) are used to measure a specific part of the neutron spectrum. For example, $(n, 2 n)$ reactions, which have thresholds in the range of 6 to 12 $\mathrm{MeV}$, are mainly sensitive to fusion neutrons that are emitted with an energy of $14 \mathrm{MeV}$. These same reactions are relatively insensitive to fission neutrons that are emitted with an average energy of $2 \mathrm{MeV}$. Other reactions with different energy thresholds, such as neutron-inelastic scattering, can be used to measure other parts of the neutron-energy spectrum.

Radiochemical detectors are chosen to yield certain radioactive products that can be easily retrieved and have suitable lifetimes and decay schemes. From measurements of radioactivity in the debris, scientists can determine for each detector the quantity of longlived radioactive products formed during the detonation. A basic ingredient in successfully using radiochemical detectors in the diagnostics of nuclear devices is an accurate knowledge of the activation cross sections of these detectors. The quantity of radioactive products produced depends on the activation cross section of the radiochemical detector and on the number and energies of the neutrons irradiating the detector. From the amount of radioactive products, scientists can deduce the neutron fluence, which is the flux integrated over time - a period that covers the entire duration of the detonation - of neutrons with sufficient energy to cause the formation of the radioactive product under investigation.

Because the neutron-energy spectrum and the location of the detector vary during the detonation of the nuclear device, the formation of reaction products from neutron irradiation of the detector is a time-dependent process. This process can only be determined from a simulation of the nuclear explosion using powerful computers. Although radiochemical detectors only provide macroscopic diagnostics, they put invaluable constraints on the simulation of nuclear detonations. 


\section{Los Alamos/Livermore Collaboration Uses the Unique Capabilities of GEANIE to Investigate Iridium and Europium Isotopes}

Scientists from Lawrence Livermore National Laboratory (LLNL) and Los Alamos National Laboratory (LANL) are studying iridium and europium isotopes because of their use in radiochemical diagnostics. These isotopes differ in their nuclear properties and therefore present different problems and challenges in measuring their activation cross sections as a function of incident-neutron energy. These cross sections have been difficult to measure by conventional means and thus have not been accurately determined - until recently. The LANL/LLNL team has developed a more accurate method for determining the activation cross sections with the use of GEANIE (Germanium Array for NeutronInduced Excitations), a large $\gamma$-ray detector array located at the Los Alamos Neutron Science Center's (LANSCE) Weapons Neutron Research Facility (WNR). GEANIE, which is equipped with planar detectors with excellent gamma-ray energy resolution (i.e., with a full-width-at-half-maximum resolution of $700 \mathrm{eV}$ at $122 \mathrm{keV}$ ), is well suited to resolve the complex and specific $\gamma$-ray cascades that subsequently will help the scientists identify the radioactive products of interest. From the intensities of measured $\gamma$-ray cascades, the scientists can use Hauser-Feshbach nuclear-model calculations to calculate the $\gamma$-ray cascades not detected in the measurement and thus determine the needed activation cross sections. Similar measurements and calculations have already been carried out successfully for the ${ }^{235} U(n, 2 n){ }^{234} U$ and ${ }^{239} \mathrm{Pu}(\mathrm{n}, 2 \mathrm{n}){ }^{238} \mathrm{Pu}$ reactions, which are very difficult to measure.

\section{Iridium Isotopes}

Natural iridium consists of ${ }^{191} \operatorname{Ir}(37.3 \%)$ and ${ }^{193} \operatorname{Ir}(62.7 \%)$ - both of which can serve as radiochemical detectors. A long-lived state in ${ }^{193} \mathrm{Ir}$ (called ${ }^{193 \mathrm{~m}} \mathrm{Ir}$, where " $\mathrm{m}$ " stands for "metastable") at an excitation energy of $80.22 \mathrm{keV}$ and with a lifetime of 10.53 days (see Fig. 1) can serve as a neutron-fluence detector most sensitive to low-energy neutrons (with energies above $80.22 \mathrm{keV}$ ) through inelastic scattering. 


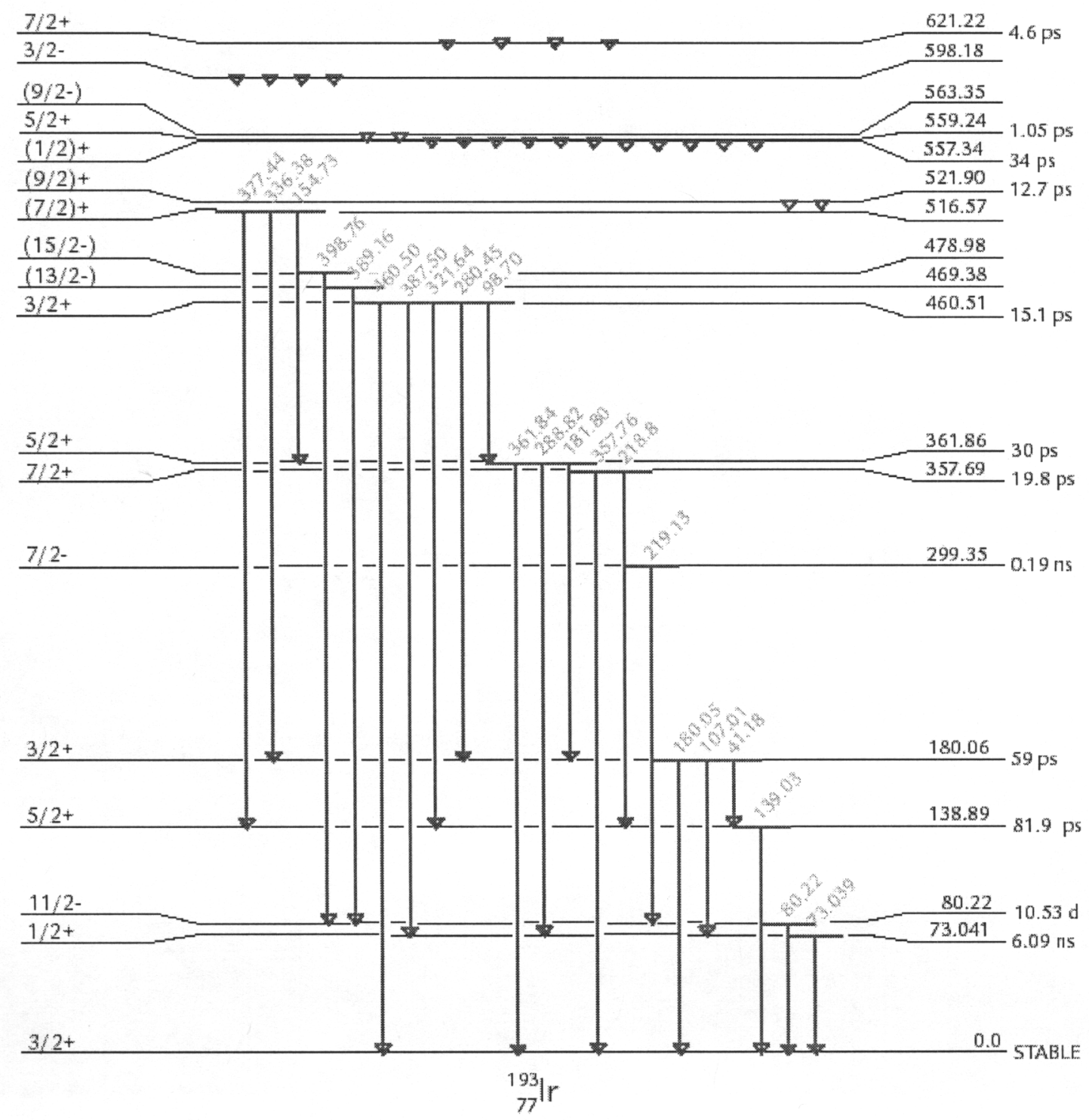

Fig. 1. Level scheme of ${ }^{193}$ Ir with $\gamma$-ray cascades from decays of these excited states. The isomeric state considered in these studies has an excitation energy of $80.22 \mathrm{keV}$ and a half-life of 10.53 days. [Level schemes obtained from Isotope Explorer 2.23 by S.Y. Chu, H. Nordberg, R.B. Firestone, and L.B. Ekstrom; http://ie.lbl.gov/isoexpl/isoexpl.htm].

The ${ }^{193 m}$ Ir state is populated (i.e., excited directly and "fed" by $\gamma$-ray cascades) by the ${ }^{193} \operatorname{Ir}\left(\mathrm{n}, \mathrm{n}^{\prime}\right){ }^{193 \mathrm{~m}} \mathrm{Ir}$ reaction (i.e., inelastic scattering in which the incident neutron loses energy in exciting the ${ }^{193}$ Ir nucleus). Only one set of measurements of the population of this state existed, in part, because of the difficulty in obtaining sufficiently intense 
monoenergetic neutron sources at energies from 6 to $13 \mathrm{MeV}$. The previous data and an evaluation (i.e., GNASH 98) are shown in Fig. 2. The recent $\gamma$-ray-cascade data obtained on GEANIE by the LANL/LLNL team and supplemented by model calculations are also shown in Fig. 2. The LANL/LLNL results are in sharp disagreement with the GNASH 98 cross-section evaluation over most of the energy range (4 to $8 \mathrm{MeV}$ ) where this cross section is large.

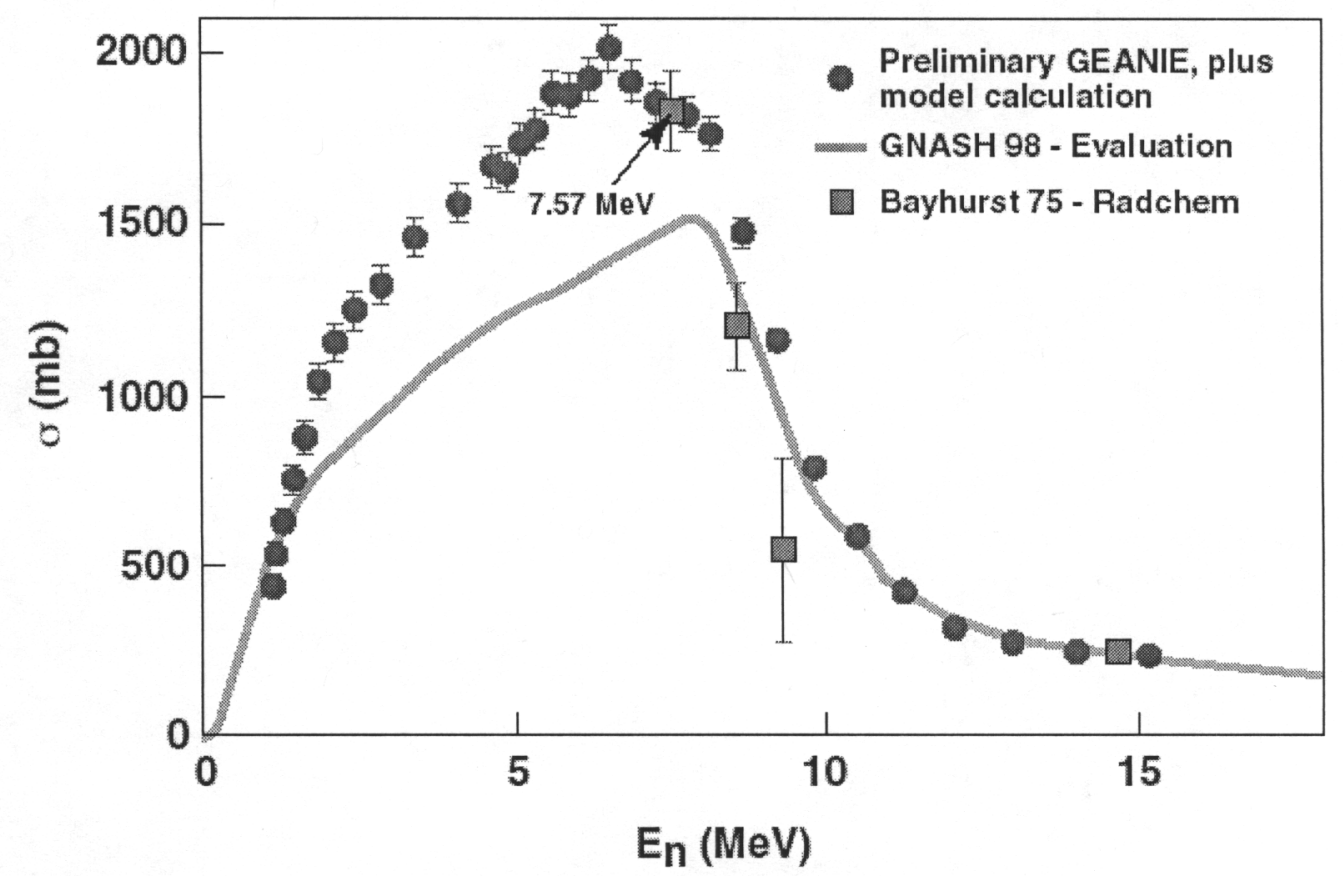

Fig. 2. Activation cross section for the ${ }^{193} \operatorname{Ir}\left(n, n^{\prime}\right){ }^{193 m} \operatorname{Ir}$ reaction. The GNASH 98 evaluated cross section is shown as a green curve. The experimental data from Bayhurst et al. are shown as solid squares. The newly obtained GEANIE results, supplemented by model calculations, are shown as solid circles.

The previous experimental data point at $7.57 \mathrm{MeV}$ is in agreement with the LANL/LLNL results but far above the cross-section evaluation at this energy. The two other similar experimental data at higher energies are, however, more in agreement with the evaluation. A new evaluation will be performed using the final GEANIE results. Results for $(n, 2 n)$ and other reactions on ${ }^{193}$ Ir will be obtained as well.

Future measurements on ${ }^{191} \mathrm{Ir}$ similar to those done on ${ }^{193} \mathrm{Ir}$ will be carried out by the LANL/LLNL team. Studies of excited states in these two iridium isotopes are also of 
interest from a nuclear structure point of view to obtain a better understanding of the shapes and excitations of these nuclei. And, as seen from the results above, better nuclear reaction modeling of the populations of the metastable states is needed.

\section{Europium Isotopes}

Natural europium consists of ${ }^{151} \mathrm{Eu}(47.3 \%)$ and ${ }^{153} \mathrm{Eu}(52.2 \%)$ - both of which can serve as radiochemical detectors. With a threshold of $7.98 \mathrm{MeV}$, the ${ }^{151} \mathrm{Eu}(\mathrm{n}, 2 \mathrm{n}){ }^{150} \mathrm{Eu}$ reaction can produce ${ }^{150} \mathrm{Eu}$ in an isomeric state (called ${ }^{150 \mathrm{~m}} \mathrm{Eu}$ ) at an excitation energy of $\mathrm{E}_{\mathrm{x}}=42.1$ $\mathrm{keV}$ and with a half-life of 12.8 hours, which is compatible with commonly used radiochemical techniques (see Fig. 3).

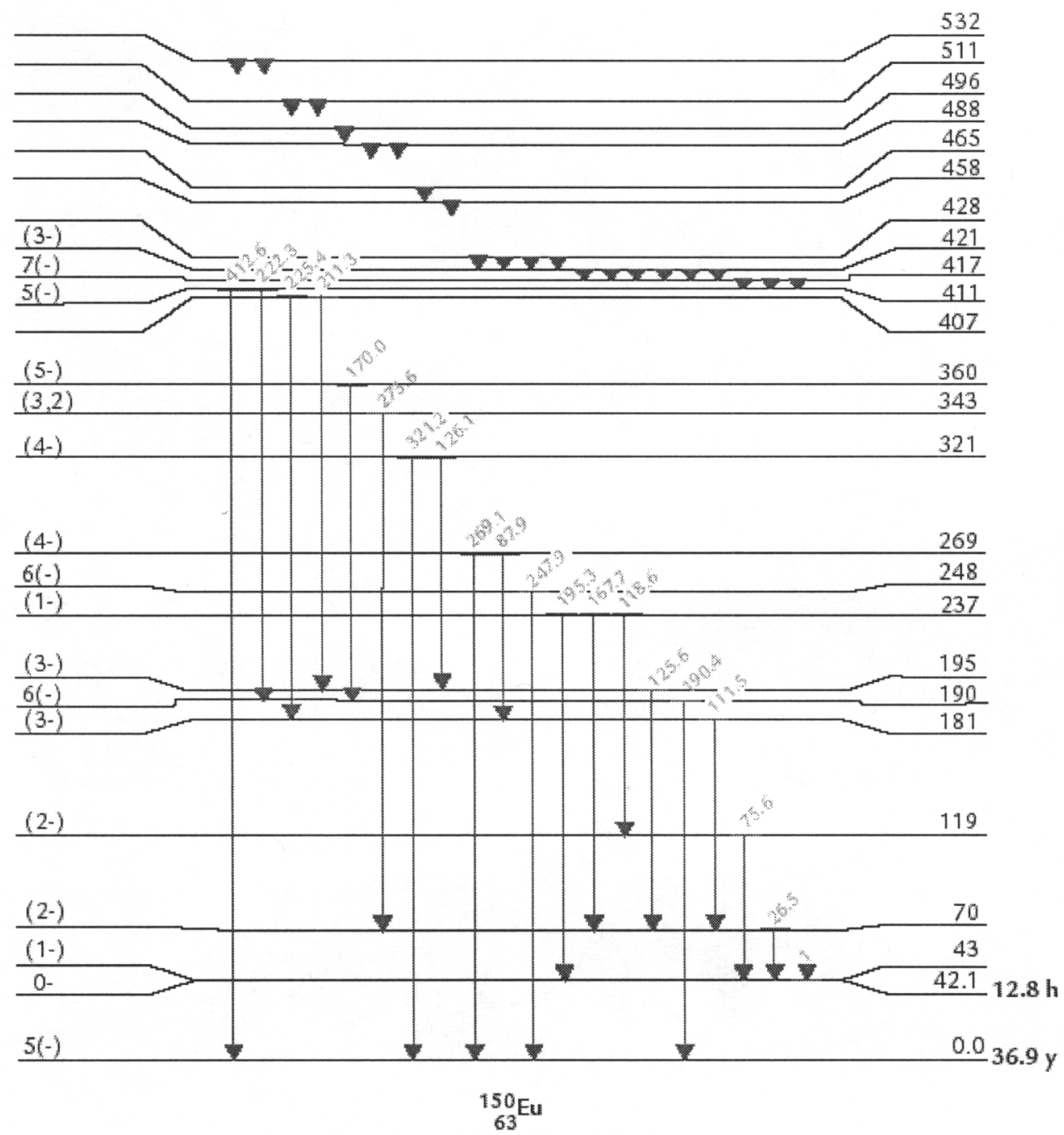

Fig. 3. Level scheme of ${ }^{150} \mathrm{Eu}$ with $\gamma$-ray cascades from decays of these excited states. The isomeric state considered in these studies has an excitation energy of $42.1 \mathrm{keV}$ and a half-life of 12.8 hours. [Level schemes obtained from Isotope Explorer 2.23 by S.Y. Chu, H. Nordberg, R.B. Firestone, and L.B. Ekstrom; http://ie.lbl.gov/isoexpl/isoexpl.htm]. 
There are, however, uncertainties in the activation cross section for the production of this isomer (see Fig. 4). The ${ }^{151} \mathrm{Eu}(\mathrm{n}, 2 \mathrm{n}){ }^{150} \mathrm{Eu}$ cross section has been measured by directly counting the two neutrons emitted in the reaction. This measurement, however, can only give the sum of the cross sections for the reactions ending with the ${ }^{150} \mathrm{Eu}$ ground state (called ${ }^{150} \mathrm{Eu}$, where "g" stands for "ground state") and ${ }^{150 \mathrm{~m}} \mathrm{Eu}$ because these two states are separated by an energy that is too small to be detected in the measurement.

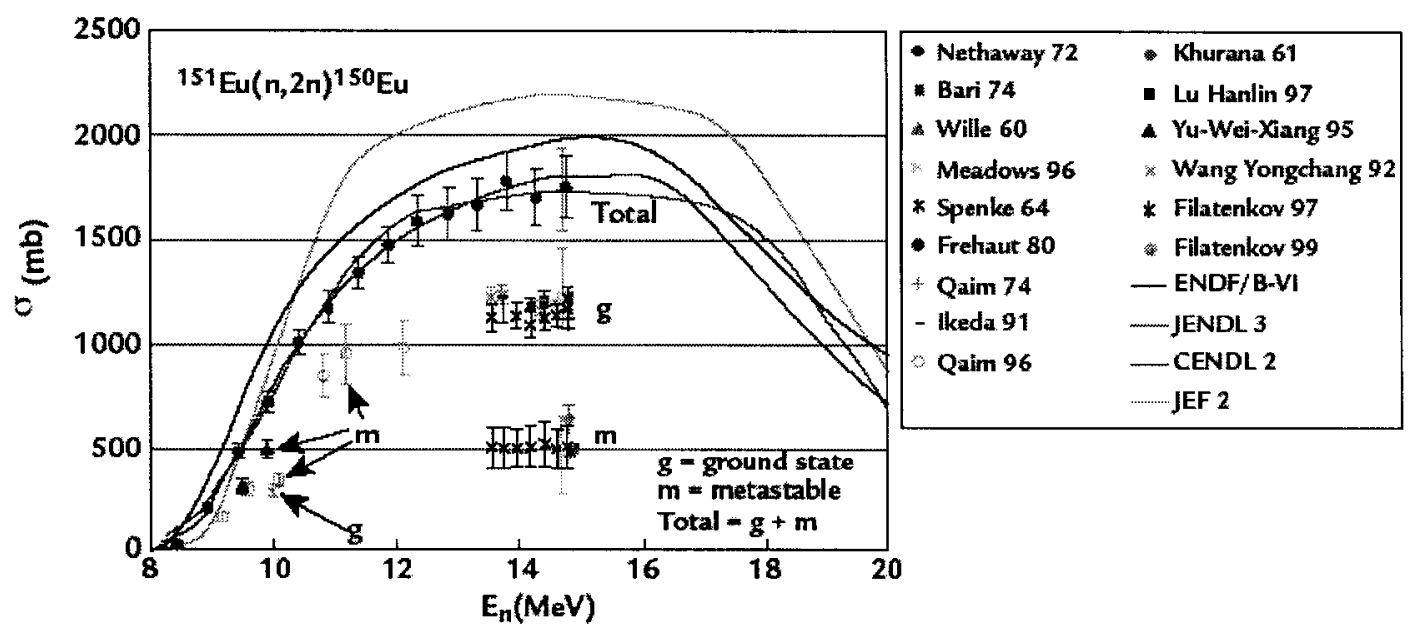

Fig. 4. Plots of ${ }^{151} \mathrm{Eu}(\mathrm{n}, 2 \mathrm{n})$ cross sections for neutron energies between 8 and 20 $\mathrm{MeV}$. Experimental data points are given for the ${ }^{151} \mathrm{Eu}(\mathrm{n}, 2 \mathrm{n})^{150 \mathrm{~g}} \mathrm{Eu}$ cross section $(\mathrm{g})$ and for the ${ }^{151} \mathrm{Eu}(\mathrm{n}, 2 \mathrm{n})^{150 \mathrm{~m}} \mathrm{Eu}$ cross section $(\mathrm{m})$. Data points and evaluated data (solid lines) are also given for the sum of these two cross sections (total $=\mathrm{g}$ $+\mathrm{m})$. [Data retrieved from the CSISRS database, ${ }^{151} \mathrm{Eu}(\mathrm{n}, 2 \mathrm{n})$ EXFOR files, with more references therein, available from the National Nuclear Data Center at http://www.nndc.bnl.gov/].

Cross sections for the ${ }^{151} \mathrm{Eu}(\mathrm{n}, 2 \mathrm{n})$ reactions that lead separately to the ground and isomeric states have been measured by radiochemical methods. The sum of the ${ }^{151} \mathrm{Eu}(\mathrm{n}, 2 \mathrm{n})^{150} \mathrm{Eu}$ and the ${ }^{151} \mathrm{Eu}(\mathrm{n}, 2 \mathrm{n})^{150 \mathrm{~m}} \mathrm{Eu}$ cross sections, as obtained from the experiments and from several evaluations, is also shown in Fig. 4. The energy of interest is $14 \mathrm{MeV}$ - the energy of fusion neutrons - and below to account for the degradation of neutron energy during the detonation of the device (down to the threshold energy of $7.98 \mathrm{MeV})$. There are uncertainties of $\pm 25 \%$ and of $\pm 10 \%$ in the ${ }^{151} \mathrm{Eu}(\mathrm{n}, 2 \mathrm{n}){ }^{150 \mathrm{~m}} \mathrm{Eu}$ and ${ }^{151} \mathrm{Eu}(\mathrm{n}, 2 \mathrm{n})$ cross sections, respectively. Reducing these errors will improve the sensitivity of the diagnostics.

GEANIE is well suited to discern the complex $\gamma$-ray cascades in ${ }^{150} \mathrm{Eu}$ - an odd-N/odd-Z nucleus. Of particular concern is the doublet of excited states at $42.1 \mathrm{keV}\left({ }^{150 \mathrm{~m}} \mathrm{Eu}\right)$ and 43 $\mathrm{keV}$ (see Fig. 3) whose $\gamma$-ray feeding must be resolved to correctly deduce the 
${ }^{151} \mathrm{Eu}(\mathrm{n}, 2 \mathrm{n}){ }^{150 \mathrm{~g}} \mathrm{Eu}$ and the ${ }^{151} \mathrm{Eu}(\mathrm{n}, 2 \mathrm{n}){ }^{150 \mathrm{~m}} \mathrm{Eu}$ cross sections. GEANIE's high resolution makes it possible to detect and separate the specific $\gamma$-ray cascades that feed the ${ }^{150 \mathrm{~m}} \mathrm{Eu}$ and ${ }^{150} \mathrm{Eu}$ levels. Moreover, knowing the formation by neutron-inelastic scattering of ${ }^{151} \mathrm{Eu}$ in its ground state and its main isomeric state at $196.245 \mathrm{keV}$, with a half-life of $58.9 \mu \mathrm{s}$, will allow a full computer simulation of the production of the isomeric state of ${ }^{150} \mathrm{Eu}$. Such a calculation will include the effect of the ${ }^{151} \mathrm{Eu}$ isomeric state for the first time.

The LLNL/LANL team has collected data on the $\gamma$-ray spectra emitted in the reactions described above and are currently in the process of analyzing these data. Preliminary results are shown in Fig. 5.

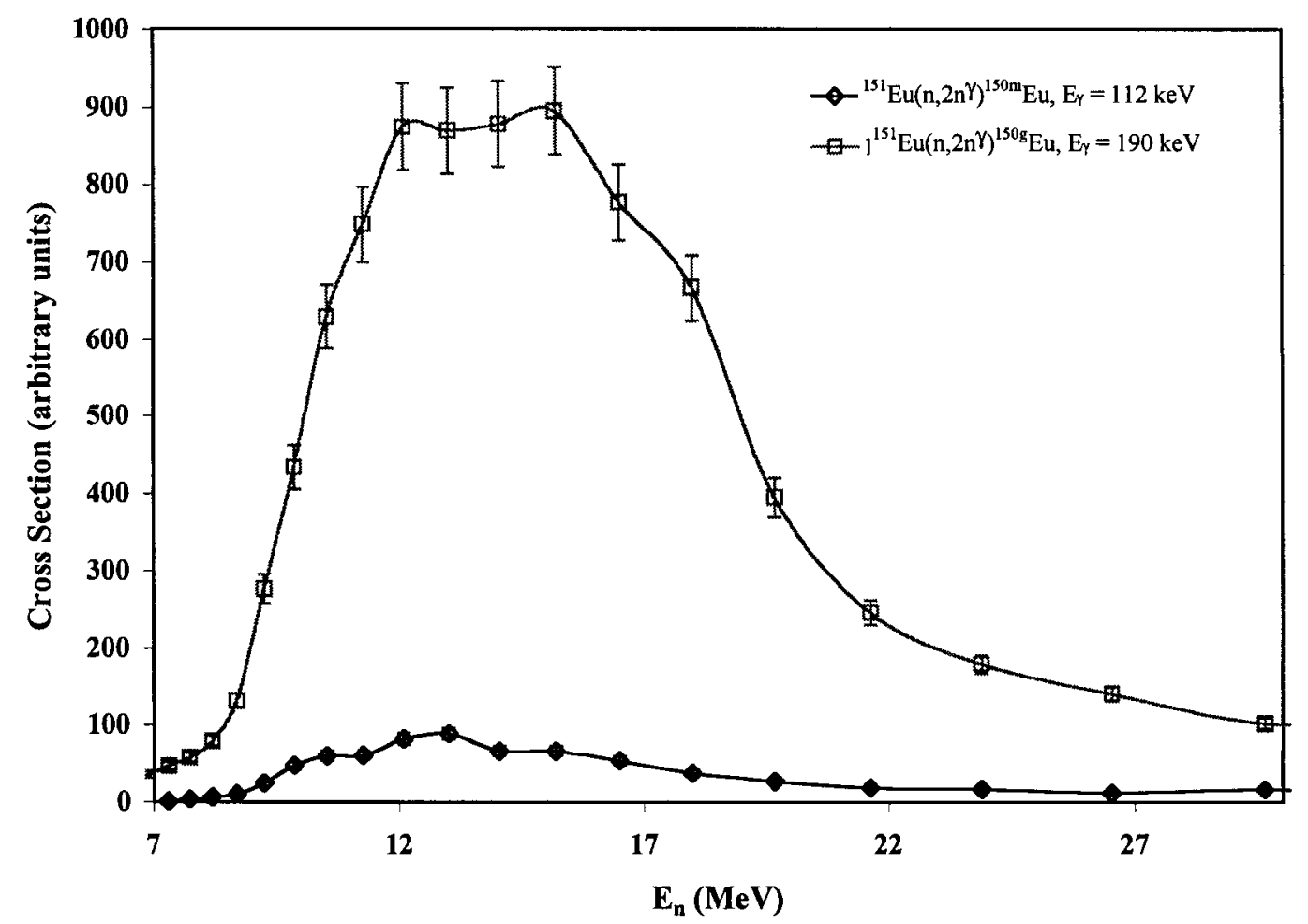

Fig. 5. Preliminary excitation functions for two of the stronger transitions observed in the ${ }^{151} \mathrm{Eu}(\mathrm{n}, 2 \mathrm{n}){ }^{150} \mathrm{Eu}$ measurement. The $190-\mathrm{keV}$ transition directly populates the ground state (squares); the $111.5-\mathrm{keV}$ transition populates the long-lived isomeric state through the $70-\mathrm{keV}$ excited state (diamonds).

\section{Conclusion}

Combining $\gamma$-ray-cascade measurements obtained on GEANIE with nuclear-reaction model calculations allows scientists to determine activation cross sections for ${ }^{193} \operatorname{Ir}\left(\mathrm{n}, \mathrm{n}^{\prime}\right){ }^{193 \mathrm{~m}} \mathrm{Ir}$ and ${ }^{151} \mathrm{Eu}(\mathrm{n}, 2 \mathrm{n}){ }^{150 \mathrm{~m}}$ Eu reactions and other cross sections useful for radiochemical diagnostics. Once these activation cross sections are accurately known, iridium and europium isotopes could be used as diagnostics to help scientists better understand the detonation of nuclear devices, as well as in other applications for which radiochemical-fluence measurements are needed. These types of data have been difficult to obtain with "standard" techniques in many cases. An added bonus is that, with 
GEANIE at WNR, the data extend to much higher incident-neutron energies (up to 200 $\mathrm{MeV}$ ) such as those found in systems for transmutation of nuclear waste or other highenergy systems that use neutrons.

Acknowledgements: The researchers would like to acknowledge financial support from the Department of Energy (DOE) and the National Nuclear Security Administration. Researchers at LLNL are supported under contract number W-7405-ENG-48.

Researchers at LANL are supported under contract number W-7405-ENG-36. This work used the LANSCE accelerator and target facilities, which are supported under DOE contract number W-7405-ENG-36.

For more information, contact the LANSCE User Office at lansce_users@lanl.gov.

Produced by members of the LANSCE communications team:

Andre Michaudon, Science Advisor

Grace Hollen, Writer/Editor

Barbara Maes, Illustration

Sharon Mikkelson, Illustration and Web Production 